This is a pre-print version. The final publication is available at Springer via

http://dx.doi.org/10.1007/978-3-319-24258-3_50

\title{
Bucket-Server: A system for including teacher-controlled flexibility in the management of learning artifacts in across-spaces learning situations
}

\author{
Juan A. Muñoz-Cristóbal ${ }^{1}$, Juan I. Asensio-Pérez ${ }^{1}$, Alejandra Martínez-Monés ${ }^{1}$, Luis \\ P. Prieto ${ }^{2}$, Iván M. Jorrín-Abellán ${ }^{3}$, Yannis Dimitriadis ${ }^{1}$ \\ ${ }^{1}$ GSIC-EMIC Group, Universidad de Valladolid, Spain \\ \{juanmunoz@gsic,juaase@tel, amartine@infor,yannis@tel\}.uva.es \\ ${ }^{2}$ CHILI research lab, École Polytechnique Fédérale de Lausanne, Switzerland \\ luis.prieto@epfl.ch \\ ${ }^{3}$ Bagwell College of Education, Kennesaw State University, GA, USA \\ ijorrina@kennesaw.edu
}

\begin{abstract}
Recent technological advances in mobile devices enable the connection of classrooms with other virtual and physical spaces. Some approaches aim at helping teachers carry out learning situations across such spaces. However, these proposals tend to be isolated from other activities in teachers' current common practices, and do not allow teacher-controlled flexibility of what students do during the enactment. Aiming to overcome such limitations, the Bucket-Server is a system that enables teachers to include learning buckets in their learning situations: containers of learning artifacts generated and/or consumed across-spaces by students during the enactment. Teachers create learning buckets at design time, configuring them with constraints to regulate the degree of freedom offered to the students. These learning buckets can be integrated into multiple existing technologies used in different educational spaces (e.g., web, physical and 3D virtual world spaces), thus helping embed buckets in the teachers' current common practices.
\end{abstract}

Keywords: Across-spaces, flexibility, augmented reality, VLE, virtual world

\section{Introduction}

Besides the physical classroom, many different virtual and physical spaces have shown affordances for learning. That is the case, for instance, of Virtual Learning Environments (VLEs), which enable both distance and face-to-face learning [1]; outdoor spaces, allowing contextual and experiential learning [2]; and even 3D virtual worlds (3DVWs), enabling the perception of objects from multiple perspectives [3]. Recent advances in technologies such as mobile devices and Augmented Reality (AR) [4] are allowing to merge such physical and virtual spaces into environments wherein a continuity of learning is possible [5]. Helping teachers achieve seamless learning across-spaces has been marked by the Technology Enhanced Learning research com-

(c) Springer International Publishing Switzerland 2015

G. Conole et al. (Eds.): EC-TEL 2015, LNCS 9307, pp. 518-521, 2015. 
munity as a key challenge to explore [6]. Thus, multiple authors have proposed solutions aimed to extend education beyond the walls of the classroom and outside the windows of VLEs $[7,8,9]$. However, such proposals tend to limit the possibilities for teachers to regulate the degree of flexibility offered to students (e.g., to choose the tools to use). Such flexibility, as well as the teachers' capability of regulating the balance between guidance and freedom offered, are important concerns in some pedagogies, such as CSCL [10]. In addition, the across-spaces learning situations supported by such proposals are typically isolated from other activities and technologies of the teachers current practice. This may negatively affect teachers' orchestration load (what some authors call the "classroom usability" [11]). The Bucket-Server system aims at aiding in such challenge, by enabling teachers to embed learning buckets in their activities, which may be carried out using several existing technologies focused on different web, physical and 3DVW spaces. The next section describes the learning bucket notion and the Bucket-Server system, and Section 3 outlines the main implications of this work.

\section{The Bucket-Server System}

The notion of learning bucket [12] was proposed with the aim of introducing flexibility in the management of learning artifacts during the enactment of across-spaces learning situations (e.g., regarding technological, contextual or arbitrary decisions). A learning bucket is a container of learning artifacts that is created by the teacher at design time, and configured with constraints. Such constraints define what the students will be able to do at enactment time within the bucket (e.g., tools allowed, maximum number of artifacts to insert, etc.), thus enabling the teacher to regulate the degree of flexibility (and coercion) provided. During the enactment, the students can use the bucket to create learning artifacts of multiple types, e.g., using existing Web 2.0 tools such as Google Drive ${ }^{1}$. The students can also position the artifacts in different spaces (e.g., web, physical and 3DVW) using a variety of positioning types (e.g., geographical coordinates, AR markers, or any other coordinates system). The buckets and the artifacts they contain can be accessed from different spaces by means of technologies commonly used in each space (e.g., VLEs in web spaces, AR apps in physical spaces and Virtual Globes [13], VGs, in 3DVW spaces).

The Bucket-Server (Fig. 1, top) is a system that implements the learning bucket notion. The Bucket-Server can be integrated with multiple existing artifact providers (including several Web 2.0 tools, widgets servers, etc.), thus enabling the population of the learning buckets with multiple kinds of artifacts. The Bucket-Server can be also integrated with multiple existing technologies focused on web (VLEs), physical (mobile AR apps) and 3DVW (VGs) spaces. This integration enables the creation of buckets from any of the aforementioned spaces (e.g., using a VLE), and access them as well as their artifacts, using other technologies in other spaces (e.g., AR apps and VGs). Fig. 1 (down) shows a basic example of the use of a learning bucket. A teacher

\footnotetext{
${ }^{1}$ https://www.google.com/drive/. Last access June 30, 2015.
} 
creates a learning bucket at design time from within a Moodle ${ }^{2}$ course and configures it with a set of constraints. During the enactment, a group of students create different learning artifacts in the bucket (in this case, Google Drive documents and presentations) regarding types of trees and monuments of the world, and position them in specific geolocations. Later on, another group of students (and also the teacher from the VLE) can access the artifacts using the Junaio ${ }^{3}$ AR app, and the 3D view of the Google Earth ${ }^{4}$ VG.

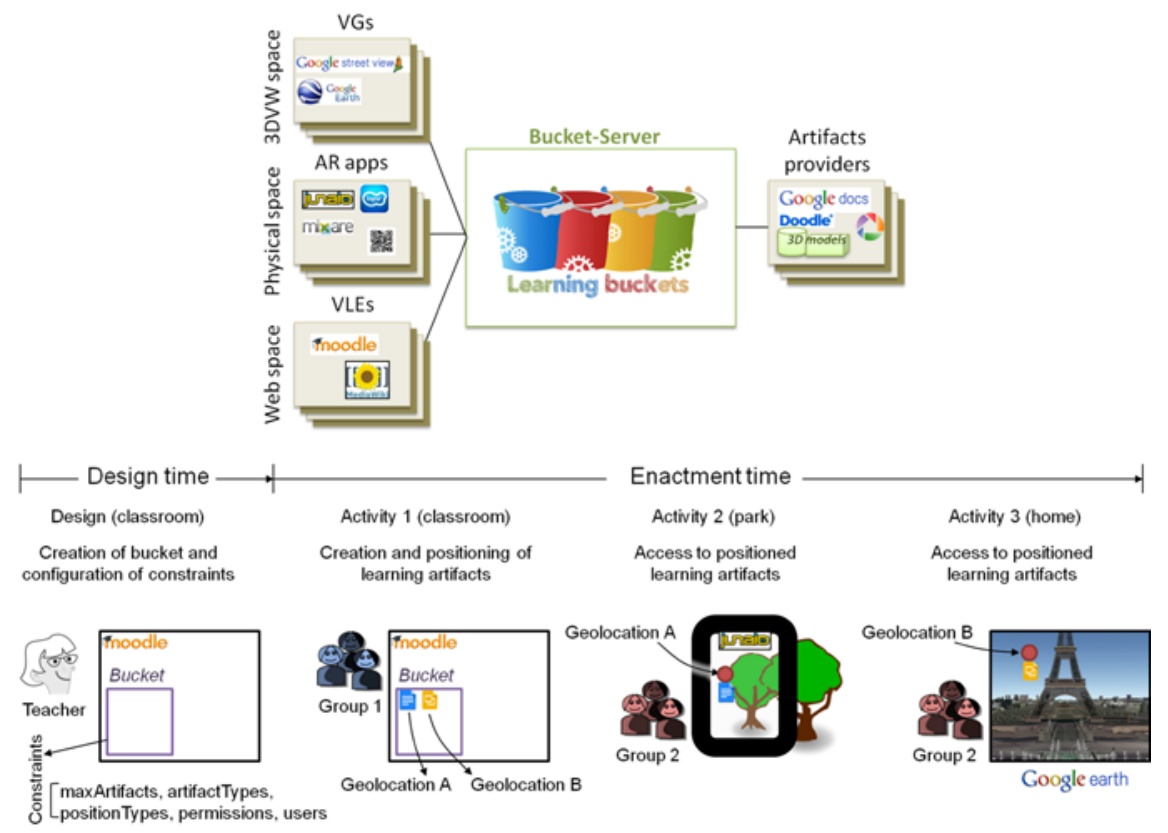

Fig. 1. The Bucket-Server system (top) and example of the use of a learning bucket (down)

\section{Conclusions}

The Bucket-Server helps solve the challenge initially described, since it enables teachers to include multiple learning buckets in the different activities of their acrossspaces learning situations, thus allowing the flexible creation and positioning of student-generated content. The Bucket-Server architecture allows teachers to choose among a wide range of technologies (of different types and for different spaces), including those of commonly used (e.g., VLEs), that are integrated in a single acrossspaces learning environment.

\footnotetext{
${ }^{2}$ https://moodle.org. Last access June 30, 2015.

${ }^{3}$ http://www.junaio.com. Last access June 30, 2015.

${ }^{4}$ https://www.google.com/earth/. Last access June 30, 2015.
} 
Acknowledgements. This research has been partially supported by the Spanish Projects TIN2011-28308-C03-02, VA277U14, the European Project 531262-LLP-2012ES-KA3-KA3MP, and the Marie Curie Fellowship FP7-PEOPLE-2012-IEF (project no. 327384). The authors thank the rest of the GSIC/EMIC research team for their ideas and support.

\section{References}

1. Keller, C.: Virtual learning environments: Three implementation perspectives. Learning, Media and Technology 30(3), 299-311 (2005).

2. Dyson, L.E., Litchfield, A., Lawrence, E., Raban, R., Leijdekkers, P.: Advancing the mlearning research agenda for active, experiential learning: Four case studies. Australasian Journal of Educational Technology 25(2), 250-267 (2009).

3. Dede, C.: Immersive interfaces for engagement and learning. Science 323(5910), 66-69 (2009).

4. Wu, H.-K., Lee, S.W.-Y., Chang, H.-Y., Liang, J.-C.: Current status, opportunities and challenges of augmented reality in education. Computers \& Education 62, 41-49 (2013).

5. Li, L., Zheng, Y., Ogata, H., Yano, Y.: A framework of ubiquitous learning environment. In: The Fourth International Conference on Computer and Information Technology (CIT 2004), pp. 345-350. Wuhan, China (2004)

6. Milrad, M., Wong, L.-H., Sharples, M., Hwang, G.-J., Looi, C.-K., Ogata, H.: Seamless learning: an international perspective on next-generation technology-enhanced learning. In: Berge, Z.L., Muilenburg, L.Y. (eds.) Handbook of Mobile Learning. pp. 95-108. Routledge, Abingdon (2013)

7. Casany, M.J., Alier, M., Mayol, E., Piguillem, J., Galanis, N., García-Peñalvo, F.J., Conde, M.Á.: Moodbile: A Framework to Integrate m-Learning Applications with the LMS. Journal of Research and Practice in Information Technology 44(2), 129-149 (2012)

8. Wong, L.-H., Looi, C.-K.: What Seams Do We Remove in Mobile-assisted Seamless Learning? A Critical Review of the Literature. Computers \& Education 57(4), 2364-2381 (2011)

9. Muñoz-Cristóbal, J.A., Prieto, L.P., Asensio-Pérez, J.I., Martínez-Monés, A., JorrínAbellán, I.M., Dimitriadis, Y.: Coming down to Earth: Helping teachers use 3D virtual worlds in across-spaces learning situations. Educational Technology \& Society 18(1), 1326 (2015)

10. Dillenbourg, P., Tchounikine, P.: Flexibility in macro-scripts for computer-supported collaborative learning. Journal of Computer Assisted Learning 23(1), 1-13 (2007)

11. Cuendet, S., Bonnard, Q., Do-Lenh, S., Dillenbourg, P.: Designing augmented reality for the classroom. Computers \& Education 68, 557-569 (2013)

12. Muñoz-Cristóbal, J.A., Prieto, L.P., Asensio-Pérez, J.I., Jorrín-Abellán, I.M., MartínezMonés, A., Dimitriadis, Y.: Sharing the Burden: Introducing Student-Centered Orchestration in Across-Spaces Learning Situations. In: Hernández-Leo, D., Ley, T., Klamma, R., Harrer, A. (eds.) Proceedings of the 8th European Conference on Technology Enhanced Learning (EC-TEL). LNCS, vol. 8095, pp. 621-622. Springer, Heidelberg (2013)

13. Rakshit, R., Ogneva-Himmelberger, Y.: Application of Virtual Globes in education. Geography Compass 2(6), 1995-2010 (2008) 